\title{
EFEITO DA TEMPERATURA DE EXTRUSÃO NA ABSORÇÃO DE ÁGUA, SOLUBILI- DADE E DISPERSIBILIDADE DA FARINHA PRÉ-COZIDA DE MILHO-SOJA (70:30) ${ }^{1}$
}

\author{
Marilene S. FERNANDES ${ }^{2}$, Sin H. WANG ${ }^{2, *}$, José Luis R. ASCHERI ${ }^{3}$,
} Myriam F. OLIVEIRA ${ }^{2}$, Simone A. J. COSTA ${ }^{2}$

\begin{abstract}
RESUMO
Com o objetivo de verificar a possibilidade do uso das farinhas pré-cozidas de milho-soja (70:30) por extrusão em produtos alimentícios, foram estudadas suas características tecnológicas. A mistura crua de milho e soja foi extrusada num extrusor Brabender de dupla-rosca com velocidade de alimentação constante de $20,8 \mathrm{Kg} / \mathrm{h}$, velocidade da rotação de parafuso de $100 \mathrm{rpm}$ e diâmetro de matriz de $5 \mathrm{~mm}$. Os perfis da temperatura de barril (TB) foram: zona $1,60^{\circ} \mathrm{C}$ (constante); zona $2,90^{\circ} \mathrm{C}$ (constante); zona $3,90,110,130$ ou $150^{\circ} \mathrm{C}$ e zona 4 (matriz), 110,130 ou $150^{\circ} \mathrm{C}$. Os resultados mostraram que, o aumento da TB nas zonas 3 e 4 causou um aumento na absorção de água nitrogênio solúvel em água, indice de solubilidade de nitrogênio, proteína dispersivel em água e índice de dispersibilidade de proteina. Não foi verificada a atividade do inibidor de tripsina nas farinhas extrusadas estudadas. Sugere-se, portanto, o uso destas nos produtos cárneos e de panificação.

Palavras-chave: extrusão; milho e soja; farinha pré-cozida; absorção de água; solubilidade de nitrogênio; dispersibilidade de proteina.
\end{abstract}

\section{SUMMARY}

EFFECT OF EXTRUSION TEMPERATURE IN WATER ABSORPTION, SOLUBILITY AND DISPERSIBILITY OF PRE-COOKED CORN-SOYBEAN (70:30) FLOURS. Pre-cooked corn-soybean (70:30) flours by extrusion were assessed for their technological characteristics in order to verify their potential use as food ingredients. The raw mixture of corn and soybean was extruded in a Brabender twin-screw extruder using a constant feed rate of $20.8 \mathrm{Kg} / \mathrm{hr}$ with constant screw speed of $100 \mathrm{rpm}$ at an exit through $5 \mathrm{~mm}$ die. The barrel temperature (BT) profile was: zone $1,60^{\circ} \mathrm{C}$ (constant); zone $2,90^{\circ} \mathrm{C}$ (constant); zone $3,90,110,130$ or $150^{\circ} \mathrm{C}$ and zone 4 (die), 110,130 or $150^{\circ} \mathrm{C}$. Results showed that, an increase in BT at zones 3 and 4 caused an increase in water absorption, water soluble nitrogen, nitrogen solubility index, water dispersible protein and protein dispersibility index. No trypsin inhibitor activity was detected in studied extruded flours. It would be desirable to use these extruded flours in meat products, bread and cakes.

Keywords: extrusion; corn and soybean; pre-cooked flour; water absorption; nitrogen solubility; protein dispersibility.

\section{1 - INTRODUÇÃO}

Alguns estudos [5, 26, 46] demonstraram os efeitos benéficos da combinação de milho e soja, através da complementação mútua de aminoácidos e do aumento do teor de proteinas totais. Além do valor nutricional, as propriedades funcionais da mistura de milho e soja podem também contribuir para êxito de uso desta mistura em sistemas alimentares [40, 41, 42].

A farinha de soja desengordurada aumentou a estabilidade e absorção de água (AA) da massa [44]. Solubilidade ou dispersibilidade das proteínas da soja é uma propriedade físico-química relacionada com as outras propriedades funcionais, razão pela qual é a primeira propriedade a ser estudada numa investigação sistemática $[15,25]$. As características de solubilidade servem como indices para otimizar os efeitos do calor nas proteinas durante os processos, de modo que sejam mostradas as vantagens e desvantagens de seus usos nos alimentos em questão. Quanto maior for o valor de solubilidade para uma proteina, melhor será a indicação do potencial de seu uso em sistemas alimentares

\footnotetext{
Recebido para publicação em 26/12/2001. Aceito para publicação em 17/09/2002 (000790).

2. Departamento de Economia Doméstica-ICHS-UFRRJ, CEP 23890-000 Seropédica, RJ.

6 EMBRAPA-CTAA (Centro Nacional de Pesquisa de Tecnologia Agroindustrial de Alimentos), Av. das Américas, 29501, CEP 23020-470 Guaratiba, RJ

* A quem a correspondência deve ser enviada.
}

[21]. O indice de solubilidade de nitrogênio (ISN) e o indice de dispersibilidade de proteína (IDP) são sempre usados como guia prático para se conhecer a funcionalidade da proteína. Sem dúvida, valores altos de ISN e IDP são muito úteis para formar uma emulsão real em produtos cárneos. No entanto, os produtos com baixos valores de ISN e de IDP podem ainda ser muito funcionais, apresentando boa AA, a qual apresenta efeito consideravelmente positivo na estabilidade do sistema cárneo [36].

O processo de extrusão tem proporcionado numerosas aplicações. Cereais matinais, petiscos, macarrões, alimentos à base de cereais enriquecidos com proteína, bebidas em pó e proteínas de soja texturizadas são alguns destes exemplos, onde a extrusão tem sido vantajosamente adotada pela indústria [6]. A extrusão propicia a obtenção de dispersões de farinhas pré-cozidas com menor viscosidade devido às modificações provocadas no material amiláceo [11]. O uso da extrusão em soja pode inativar efetivamente a lipoxigenase e os inibidores de tripsina, mantendo a disponibilidade de lisina [2, 14, 45], além de modificar suas estrutura e textura como conseqüência das alterações ocorridas na proteina [32].

Desta forma, este trabalho teve como objetivo avaliar a AA, a solubilidade e a dispersibilidade das farinhas de milho-soja (70:30) pré-cozidas por extrusão, verificando o efeito da temperatura de extrusão e visando a possibilidade de utilizá-las na melhoria de características tecnológicas de produtos alimenticios. 


\section{2 - MATERIAL E MÉTODOS}

\section{1 - Material}

As matérias-primas usadas para os estudos foram canjiquinha de milho (Zea mays) e grãos de soja (Glycine $\max ($ L.) Merril, cultivar BRS-155, safra de 1999), ambos adquiridos do comércio e da EMBRAPA-CNPSO (Londrina, $P R)$, respectivamente.

\section{2 - Métodos}

A obtenção da farinha extrusada e todas as análises quimicas, fisicas e da atividade do inibidor de tripsina, que se seguem, foram feitas em triplicata.

Para canjiquinha de milho, grãos de soja integrais e decorticados, e farinha mista crua de milho-soja (70:30) foram realizadas as análises de umidade, extrato etéreo, proteína bruta e cinzas, segundo os métodos de AACC [1], e fibra bruta, conforme o método descrito por VAN DE KAMER \& VAN GINKEL [35].

Os grãos de soja foram decorticados e branqueados, usando-se a metodologia de WANG et al [39]. Em seguida, os mesmos grãos de soja foram misturados com a canjiquinha de milho na proporção de 30:70 (base seca), sendo desintegrados num moinho de facas e martelos, com peneira de $2 \mathrm{~mm}$, obtendo-se uma farinha mista crua de milho-soja com aproximadamente $21 \%$ de umidade. A mesma farinha mista crua foi extrusada em extrusor Brabender de dupla rosca, usando-se uma velocidade de alimentação constante de $20,8 \mathrm{Kg} / \mathrm{h}$, uma velocidade da rotação de parafuso de $100 \mathrm{rpm}$ e um diâmetro de matriz de $5 \mathrm{~mm}$. Os perfis da temperatura de barril do extrusor foram: zona $1,60^{\circ} \mathrm{C}$ (constante); zona $2,90^{\circ} \mathrm{C}$ (constante); zona $3,90,110,130$ ou $150^{\circ} \mathrm{C}$ e zona 4 (matriz), 110,130 ou $150^{\circ} \mathrm{C}$. Os produtos extrusados foram designados nas seguintes seqüências: 90-110 (A), 90130 (B), 90-150 (C), 110-110 (D), 110-130 (E), 110-150 $(\mathrm{F}), 130-130(\mathrm{G}), 130-150(\mathrm{H}), 150-150(\mathrm{I})$. Esses produtos foram secos numa estufa a $60^{\circ} \mathrm{C}$ com circulação de ar por um tempo de 5-6h, obtendo-se os produtos expandidos com aproximadamente $4-5 \%$ de umidade. Estes foram moídos, em seguida, num moinho de martelo para se obter várias farinhas extrusadas de milho-soja com aproximadamente $4-7 \%$ de umidade.

Foram peneiradas $60 \mathrm{~g}$ de farinha extrusada, durante $15 \mathrm{~min}$, num conjunto de sete peneiras arredondadas, vibratórias e com as aberturas das malhas variando de 20 mesh $(0,84 \mathrm{~mm})$ a 200 mesh $(0,074 \mathrm{~mm})$. Logo após, as quantidades retidas em cada peneira foram pesadas e expressas em percentagens.

A absorção de água (AA) foi determinada, segundo o método descrito por SOSULSKI [33].

Foi determinada a percentagem de nitrogênio solúvel em água (NSA), conforme o método 46-23 descrito pela AACC [1], destacando-se pela técnica de lenta agitação. $O$ indice de solubilidade de nitrogênio (ISN) foi calculado pela relação:
$\%$ ISN $=\frac{\% \text { NSA }}{\% \text { Nitrogênio Total }} \times 100$

Determinou-se a percentagem de proteina dispersivel em água (PDA), de acordo com o método 46-24, descrito pela AACC [1], destacando-se pela técnica de rápida agitação. $O$ indice de dispersibilidade de proteína (IDP) foi calculado pela relação:

$$
\% \mathrm{IDP}=\frac{\% \text { PDA }}{\% \text { Proteína Total }} \times 100
$$

Foi analisada a atividade do inibidor de tripsina para as amostras que apresentaram maiores valores de AA, ISN e IDP, usando-se o método descrito por KAKADE, SIMONS, LIENER [20].

Para os resultados de composição centesimal aproximada das matérias-primas, classificação granulométrica, AA, NSA, ISN, PDA e IDP das farinhas extrusadas, foi usado o Delineamento Inteiramente Casualizado (DIC), onde foram feitas as análises de variância, com posterior comparação das diferenças entre as médias pelo teste de Tukey ao nivel de $5 \%$ de probabilidade. Também foram determinados os coeficientes de correlação entre os parâmetros de propriedades funcionais.

A análise estatística foi realizada, conforme os métodos descritos por PIMENTEL GOMES [31] e COCHRAN \& $\operatorname{COX}[9]$.

\section{3 - RESULTADOS E DISCUSSÃO}

A Tabela 1 apresenta, em base seca, a composição centesimal aproximada da canjiquinha de milho, dos grãos de soja integrais e decorticados, e da farinha mista crua de milho-soja (70:30).

TABELA 1. Composição centesimal aproximada (\% base seca) da canjiquinha de milho, dos grãos de soja integrais e decorticados, e da farinha mista crua de milho-soja (70:30) ${ }^{1}$.

\begin{tabular}{lcrrrrrr}
\hline $\begin{array}{c}\text { Composição } \\
(\%)\end{array}$ & $\begin{array}{c}\text { Canj iquinha } \\
\text { de milho }\end{array}$ & $\begin{array}{c}\text { Soja } \\
\text { integral }\end{array}$ & $\begin{array}{c}\text { Soja } \\
\text { decorticada }\end{array}$ & $\begin{array}{c}\text { Farinha } \\
\text { mista crua }\end{array}$ & D.M.S. & C.V. \\
\hline Proteína bruta & $7,84 \mathrm{D}$ & $41,16 \mathrm{~B}$ & $44,57 \mathrm{~A}$ & $18,38 \mathrm{C}$ & 1,34 & 1,97 \\
Extrato etéreo & $0,49 \mathrm{D}$ & $20,97 \mathrm{~B}$ & $23,62 \mathrm{~A}$ & $7,05 \mathrm{C}$ & 0,33 & 1,07 \\
Cinzas & $0,29 \mathrm{D}$ & $5,69 \mathrm{~A}$ & $5,54 \mathrm{~B}$ & $1,82 \mathrm{C}$ & 0,15 & 1,90 \\
Fibra bruta & $0,44 \mathrm{D}$ & $5,93 \mathrm{~A}$ & $3,67 \mathrm{~B}$ & $1,37 \mathrm{C}$ & 0,20 & 3,06 \\
Carboidratos $^{2}$ & $90,94 \mathrm{~A}$ & $26,25 \mathrm{C}$ & $22,60 \mathrm{D}$ & $71,38 \mathrm{~B}$ & 1,18 & 0,76 \\
\hline
\end{tabular}

${ }^{1}$ As médias, na mesma linha, seguidas de letra diferente diferem estatisticamente entre si pelo teste de Tukey ao nivel de $5 \%$ de probabilidade

${ }^{2}$ Calculado por diferença (100 - proteína - extrato etéreo - cinzas - fibra bruta).

Através desta tabela, observa-se que a composição centesimal aproximada obtida para a canjiquinha de milho foi semelhante àquela encontrada por BORGES et al [4]. A soja estudada apresentou maiores teores de proteína bruta, extrato etéreo, cinzas e fibra bruta do que a canjiquinha de milho, tendo sido superiores aos valores obtidos por MAIA et al [24], devido à diferença de cultivar e do ano de plantio. Os grãos de soja decorticados 
mostraram maiores conteúdos de proteína bruta e extrato etéreo do que os da soja integral. O alto teor de fibra bruta encontrado para a soja integral indica que a casca contém grande quantidade deste componente. Por outro lado, a canjiquinha de milho mostrou o maior teor de carboidratos.

Verifica-se ainda que, os teores de proteína bruta (de 7,84 a 18,38\%), extrato etéreo (de 0,49 a 7,05\%), cinzas (de 0,29 a 1,82\%) e fibra bruta (de 0,44 a 1,37\%) aumentaram com a adição de soja (de 0 a $30 \%$ ) na farinha de milho, sendo que o aumento foi mais notável nos conteúdos de proteína bruta e extrato etéreo. Porém, o percentual de carboidratos (de 90,94 a 71,38\%) diminuiu com a adição de soja. Resultados quanto à composição centesimal aproximada da farinha mista crua de milho-soja (70:30) são semelhantes aos encontrados por GUTIÉRREZ \& GÓMEZ [13].

A distribuição do tamanho de partículas das farinhas extrusadas de milho-soja (70:30) em diferentes temperaturas está apresentada na Tabela 2.

TABELA 2. Distribuição (\%) do tamanho de partículas das farinhas extrusadas de milho-soja (70:30) em diferentes temperaturas $^{1}$.

\begin{tabular}{|c|c|c|c|c|c|c|c|c|c|c|}
\hline \multicolumn{2}{|c|}{$\begin{array}{c}\text { Temperatura de } \\
\text { barril }\end{array}$} & \multirow{2}{*}{$\begin{array}{l}\text { Farinha } \\
\text { extrusada }\end{array}$} & \multicolumn{8}{|c|}{ Mesh (tyler) } \\
\hline Zona 3 & $\overline{\text { Zona 4 }}$ & & 20 & 40 & 60 & 80 & 100 & 150 & 200 & $\begin{array}{l}\text { Fundo } \\
<200\end{array}$ \\
\hline \multirow[t]{3}{*}{90} & 110 & $\overline{\mathrm{A}}$ & $0,10 \mathrm{~d}$ & $39,30 \mathrm{ef}$ & $39,60 \mathrm{~d}$ & $10,20 \mathrm{c}$ & $8,70 \mathrm{a}$ & $1,90 \mathrm{a}$ & $0,20 \mathrm{a}$ & $\overline{0,00}$ \\
\hline & 130 & B & $0,20 \mathrm{~cd}$ & $40,20 \mathrm{~d}$ & $38,00 \mathrm{e}$ & $19,80 \mathrm{a}$ & $1,80 \mathrm{~b}$ & $0,00 \mathrm{~b}$ & $0,00 \mathrm{a}$ & 0,00 \\
\hline & 150 & $\mathrm{C}$ & $1,00 \mathrm{a}$ & $41,40 \mathrm{c}$ & $34,60 \mathrm{f}$ & $21,20 \mathrm{a}$ & $1,40 \mathrm{~b}$ & $0,30 \mathrm{~b}$ & $0,10 \mathrm{a}$ & 0,00 \\
\hline \multirow[t]{3}{*}{110} & 110 & D & $0,20 \mathrm{~cd}$ & $45,10 \mathrm{a}$ & $34,10 \mathrm{f}$ & $20,40 \mathrm{a}$ & $0,20 c$ & $0,00 \mathrm{~b}$ & $0,00 \mathrm{a}$ & 0,00 \\
\hline & 130 & E & $0,20 \mathrm{~cd}$ & $40,10 \mathrm{de}$ & $38,80 \mathrm{de}$ & $20,70 \mathrm{a}$ & $0,20 c$ & $0,00 \mathrm{~b}$ & $0,00 \mathrm{a}$ & 0,00 \\
\hline & 150 & F & $0,30 \mathrm{c}$ & $35,80 \mathrm{~g}$ & $43,10 \mathrm{~b}$ & $20,60 \mathrm{a}$ & $0,20 \mathrm{c}$ & $0,00 \mathrm{~b}$ & $0,00 \mathrm{a}$ & 0,00 \\
\hline \multirow[t]{2}{*}{130} & 130 & G & $0,50 \mathrm{~b}$ & $42,60 \mathrm{~b}$ & $41,10 c$ & $15,70 \mathrm{~b}$ & $0,10 \mathrm{c}$ & $0,00 \mathrm{~b}$ & $0,00 \mathrm{a}$ & 0,00 \\
\hline & 150 & $\mathrm{H}$ & $0,60 \mathrm{~b}$ & $35,10 \mathrm{~g}$ & $44,40 \mathrm{a}$ & $19,90 \mathrm{a}$ & $0,00 c$ & $0,00 \mathrm{~b}$ & $0,00 \mathrm{a}$ & 0,00 \\
\hline 150 & 150 & I & $0,60 \mathrm{~b}$ & $39,00 \mathrm{f}$ & $43,10 \mathrm{~b}$ & $17,30 \mathrm{~b}$ & $0,00 \mathrm{c}$ & $0,00 \mathrm{~b}$ & $0,00 \mathrm{a}$ & 0,00 \\
\hline \multicolumn{2}{|c|}{ D.M.S. } & & 0,16 & 0,81 & 1,04 & 1,66 & 0,71 & 0,49 & 0,21 & - \\
\hline \multicolumn{2}{|c|}{ C.V. (\%) } & & 14,04 & 0,71 & 0,92 & 3,15 & 17,66 & 69,53 & 223,61 & 0 \\
\hline
\end{tabular}

${ }^{1}$ As médias, na mesma coluna, seguidas de letra diferente diferem estatisticamente

entre si pelo teste de Tukey ao nivel de $5 \%$ de probabilidade.
${ }^{1}$ Temperatura no extrusor: zona $1,60^{\circ} \mathrm{C}$ (constante); zona $2,90^{\circ} \mathrm{C}$ (constante).

Através dos dados apresentados, verifica-se que a distribuição do tamanho de partículas das farinhas extrusadas de milho-soja não foi afetada pelas diferentes temperaturas de barril (TB) usadas no extrusor, indicando que houve homogeneidade no tamanho de partículas nessas farinhas. Exceto para farinhas submetidas à TB a 60-90-90-110 ${ }^{\circ} \mathrm{C}$, a maioria das particulas $(98,00$ a $99,60 \%)$ das farinhas extrusadas foram retidas nas peneiras de 40 a 80 mesh. A TB correspondente a $60-90-90-110^{\circ} \mathrm{C}$ não foi suficiente para aumentar o tamanho de partícula das farinhas extrusadas de milhosoja, sugerindo-se a menor possibilidade da interação entre os componentes das mesmas nesta TB.

Absorção de água (AA), nitrogênio solúvel em água (NSA), indice de solubilidade de nitrogênio (ISN), proteína dispersivel em água (PDA) e indice de dispersibilidade de proteina (IDP) das farinhas extrusadas de milho-soja (70:30) em diferentes temperaturas estão mostradas na Tabela 3.
TABELA 3. Absorção de água (AA), nitrogênio solúvel em água (NSA), indice de solubilidade de nitrogênio (ISN), proteína dispersivel em água (PDA) e índice de dispersibilidade de proteína (IDP) das farinhas extrusadas de milho-soja (70:30) em diferentes temperaturas ${ }^{1}$.

\begin{tabular}{|c|c|c|c|c|c|c|c|}
\hline \multicolumn{2}{|c|}{$\begin{array}{c}\text { Temperatura } \\
\text { de barril }\end{array}$} & \multirow{2}{*}{$\begin{array}{l}\text { Farinha } \\
\text { ex trusada }\end{array}$} & \multirow{2}{*}{$\begin{array}{c}\text { AA } \\
(\% \text { b.s. })\end{array}$} & \multirow{2}{*}{$\begin{array}{l}\text { NSA } \\
(\% \text { b.s. })\end{array}$} & \multirow{2}{*}{$\begin{array}{l}\text { ISN } \\
(\%)\end{array}$} & \multirow{2}{*}{$\begin{array}{l}\text { PDA } \\
(\% \text { b.s. })\end{array}$} & \multirow{2}{*}{$\begin{array}{l}\text { IDP } \\
(\%)\end{array}$} \\
\hline zona 3 & zona 4 & & & & & & \\
\hline \multirow[t]{3}{*}{90} & 110 & $\overline{\mathrm{A}}$ & $464,13 \mathrm{e}$ & $0,13 b$ & $4,36 \mathrm{~d}$ & $0,65 \mathrm{~g}$ & $3,58 \mathrm{~g}$ \\
\hline & 130 & B & $481,54 d$ & $0,13 b$ & $4,50 \mathrm{~cd}$ & $0,71 \mathrm{f}$ & $3,88 \mathrm{f}$ \\
\hline & 150 & $\mathrm{C}$ & $479,28 \mathrm{~d}$ & $0,14 \mathrm{~b}$ & $4,59 \mathrm{~cd}$ & $0,91 \mathrm{c}$ & $4,97 \mathrm{c}$ \\
\hline \multirow[t]{3}{*}{110} & 110 & D & $478,86 \mathrm{de}$ & $0,13 b$ & $4,38 \mathrm{~d}$ & $0,83 \mathrm{e}$ & $4,56 \mathrm{e}$ \\
\hline & 130 & E & $489,83 \mathrm{~cd}$ & $0,14 \mathrm{~b}$ & $4,68 \mathrm{bcd}$ & $0,85 \mathrm{de}$ & $4,67 \mathrm{de}$ \\
\hline & 150 & F & $484,93 \mathrm{~cd}$ & $0,15 \mathrm{ab}$ & $4,90 \mathrm{bcd}$ & $0,92 \mathrm{c}$ & $4,99 \mathrm{c}$ \\
\hline \multirow[t]{2}{*}{130} & 130 & G & $497,68 \mathrm{c}$ & $0,15 \mathrm{ab}$ & $5,16 a b c$ & $0,89 \mathrm{~cd}$ & $4,85 \mathrm{~cd}$ \\
\hline & 150 & $\mathrm{H}$ & $523,39 \mathrm{~b}$ & $0,17 \mathrm{a}$ & $5,69 \mathrm{a}$ & $1,13 \mathrm{a}$ & $6,18 \mathrm{a}$ \\
\hline 150 & 150 & I & $546,80 \mathrm{a}$ & $0,15 \mathrm{ab}$ & $5,33 \mathrm{ab}$ & $1,04 \mathrm{~b}$ & $5,67 \mathrm{~b}$ \\
\hline \multicolumn{2}{|c|}{ D.M.S. } & & 15,12 & 0,03 & 0,68 & 0,04 & 0,23 \\
\hline \multicolumn{2}{|c|}{ C.V. (\%) } & & 1,07 & 7,14 & 4,93 & 1,79 & 1,64 \\
\hline
\end{tabular}

${ }^{1}$ As médias, na mesma coluna, seguidas de letra diferente diferem estatisticamente entre si pelo teste de Tukey ao nivel de $5 \%$ de probabilidade.

${ }^{1}$ Temperatura no extrusor: zona $1,60^{\circ} \mathrm{C}$ (constante); zona $2,90^{\circ} \mathrm{C}$ (constante)

Nota-se que os valores de AA aumentaram, à medida que aumentava a TB tanto na zona 3 quanto na zona 4. Resultados semelhantes de AA foram verificados por GONZÁLEZ et al. [11] e GUTIÉRREZ \& GÓMEZ [13], os quais constataram que a AA está relacionada com a capacidade de intumescimento dos grânulos de amido, enquanto que se mantem a morfologia dos mesmos. Segundo esses autores, a AA do amido de milho aumentou com o aumento da temperatura do extrusor até $140^{\circ} \mathrm{C}$ nos niveis de umidade entre 25 e 35\%, além do qual, a AA passou a diminuir, devido à alteração da integridade dos grânulos de amido. A redução de AA do amido de milho extrusado com o aumento da TB $\left(80\right.$ a $\left.160^{\circ} \mathrm{C}\right)$ foi também verificada por TANG \& DING [34] em baixo conteúdo de umidade (20\%).

De acordo com GOMEZ \& AGUILERA [10], as modificações que ocorrem com a AA no processo de extrusão podem depender, não só da disponibilidade de grupos hidrofilicos que ligam as moléculas de água, mas também da capacidade formadora de gel das macromoléculas como farinha de milho gelatinizada ou dextrinizada.

$\mathrm{O}$ efeito da proteina na AA é bastante discutivel. NATH \& RAO [27] constataram existência de uma conformação de proteina, permitindo que os sitios ligantes sejam estericamente disponiveis para a interação com as moléculas de água. O impedimento estérico destes sítios pode resultar em baixos valores de AA. Conforme WAGNER \& AÑON [38], uma alta hidrofobicidade na superficie de proteínas desnaturadas do isolado protéico de soja, pode promover a formação de uma matriz de proteína (estabilizada pelas interações hidrofóbicas) capaz de reter quantidade significativa de água em sua estrutura. Além disso, um baixo número de grupos -SH também é um fator determinante da AA. Num conteúdo semelhante de grupos - $\mathrm{SH}$, um aumento na hidrofobicidade da estrutura de proteinas pode produzir 
um incremento da $\mathrm{AA}$, enquanto que na mesma hidrofobicidade, um aumento de grupos - $\mathrm{SH}$ pode induzir uma perda da AA. Por outro lado, numa proteína completamente desnaturada, pode ser encontrada uma baixa AA.

A proteina de soja diminui a AA do amido de arroz, sendo verificada por vários autores $[6,7,23,28]$, os quais demonstraram que a AA é o resultado do amido gelatinizado e dos componentes insolúveis. Assim, segundo GUJSKA \& KHAN [12], a natureza do amido e da proteína, e o tipo dos complexos de amido-proteína formados podem ter afetado AA.

Por outro lado, HORVÁTH et al. [17] observaram que as farinhas de soja extrusadas à temperatura de 120 e $160^{\circ} \mathrm{C}$, respectivamente, mostraram os mesmos valores de AA. Porém, a AA diminuiu quando a temperatura de extrusão aumentou para $200^{\circ} \mathrm{C}$. Resultados semelhantes foram também encontrados no presente trabalho, usando-se TB de $90-130$ e $90-150^{\circ} \mathrm{C}$, e, 110-130 e 110$150^{\circ} \mathrm{C}$, nas respectivas zonas 3 e 4.

A AA é uma propriedade relevante para aplicações em produtos cárneos, pães e bolos, segundo JAMES \& SLOAN [19], para os quais, valores altos de AA são importantes para ajudar a manter a umidade dos mesmos. Desta maneira, os valores altos da AA encontrados nas farinhas extrusadas de milho-soja estudadas, podem ser desejáveis na utilização destas nos produtos cárneos e de panificação, pois permite a adição de mais água à massa, melhorando suas características de manuseio.

De acordo com WHALEN et al. [43], as modificações que ocorrem durante o processo de extrusão nos materiais contendo amido, são algo refletidas pela sua solubilidade e absorção em água, as quais são respostas de produtos como dextrinas, polimeros grandes, amidos intumescidos, entrelaçamentos de polimeros pequenos, formados na transformação de seu amido.

Analisando-se ainda a Tabela 3, verifica-se que os valores de NSA, ISN, PDA e IDP aumentaram à medida que se aumentou a TB tanto na zona 3 quanto na zona 4, exceto para aquelas submetidas à TB de 60-90-150150 , as quais mostraram valores em decréscimo.

BORDERÍAS \& MONTERO [3] relataram que a solubilidade de proteína depende diretamente da proporção dos grupos hidrofóbicos localizados no centro da molécula, e dos grupos hidrofilicos localizados na superficie.

HORVÁTH et al [17] verificaram que o ISN da farinha de soja diminuiu com o aumento da temperatura de extrusão, sendo grande variação (de 62,2 a 15,5\%) observada quando a temperatura de matriz aumentou de 120 a $160^{\circ} \mathrm{C}$. De forma semelhante, ZHU, RIAZ, LUSAS [45] observaram que o IDP diminuiu significativamente, enquanto que a temperatura de extrusão aumentava, exceto para $116^{\circ} \mathrm{C}$. Um aumento no conteúdo de umidade (de 9,2 para 16,3\%) na soja, durante a extrusão, resultou também num rápido e significativo decréscimo de IDP (de 68,4 para 24,2\%).

A diminuição da solubilidade de proteína pode ser devido, conforme HORVÁTH \& CZUKOR [16], ao fato da ocorrência de desnaturação das proteinas de soja, e de acordo com PHAM \& DEL ROSÁRIO [30], esta redução pode ser atribuída às interações não covalentes entre cadeias de polipeptídeos, à formação de novas ligações dissulfídicas ou de ligações não peptídicas envolvendo grupos carboxilicos e amínicos.

Por outro lado, NOGUCHI et al. [28] relataram que, apesar da diminuição da solubilidade do isolado protéico de soja (IPS) causada por extrusão, houve uma alta solubilidade de proteina quando o IPS e a farinha de arroz foram extrusados simultaneamente, mostrando um "efeito protetor" do amido de arroz ou de outros constituintes não-protéicos contra a formação de interações não covalentes, ligações dissulfidicas e outras covalentes. Resultados semelhantes foram também verificados por NYANZI \& MAGA [29], os quais constataram que, a mistura de amido de milho e IPS extrusada a $150^{\circ} \mathrm{C}$ apresentou maior solubilidade de proteina do que aquela submetida a $100^{\circ} \mathrm{C}$, o que foi atribuído, segundo os mesmos autores, à clivagem térmica de certos polipeptídeos susceptiveis a $150^{\circ} \mathrm{C}$.

Portanto, sugere-se que no presente trabalho, o aumento da TB tenha contribuido para a desnaturação da proteína, o que por conseqüência, pode ter resultado numa hidrólise da proteína, favorecendo posteriormente a reação de Maillard com amidos fragmentados como maltose e glicose, explicando-se desta forma, o aumento da solubilidade de proteína verificado até TB de 130$150^{\circ} \mathrm{C}$ nas respectivas zonas 3 e 4 , e também o seu decréscimo encontrado além desta.

O ISN teve correlação positiva com o NSA, apresentando coeficiente de correlação igual a 0,9196, significativo ao nivel de $5 \%$ de probabilidade, mostrando que o ISN aumentou com o aumento do NSA. O mesmo comportamento foi observado entre IDP e PDA, apresentando coeficiente de correlação igual a 0,9974, significativo ao nivel de $5 \%$ de probabilidade. Foram verificadas correlações positivas entre NSA x PDA e ISN x IDP da farinha extrusada de milho-soja, apresentando coeficientes de correlação respectivamente iguais a 0,7371 e 0,7959, significativos ao nivel de $5 \%$ de probabilidade, embora acredite-se que nem sempre a PDA contribua para o NSA, ou seja, uma proteina pode ser dispersivel em água, mas ela não é necessariamente solúvel em água. Porém, o IDP e o ISN são intimamente relacionados, o que é demonstrado por VOLKERT \& KLEIN [37] num estudo do IDP e por HUTTON \& CAMPBELL [18] num estudo do ISN em diferentes produtos de soja (isolado, concentrado e flocos). Os resultados obtidos com o IDP foram semelhantes àqueles encontrados com o ISN.

A solubilidade de proteína (NSA, ISN, PDA e IDP) da farinha extrusada de milho-soja se correlacionou positivamente com a AA, apresentando coeficientes de correlação respectivamente iguais a $0,5718,0,7689,0,8038$ e 0,8032, significativos ao nivel de $5 \%$ de probabilidade.

Segundo HUTTON \& CAMPBELL [18], a solubilidade (ISN) e a AA podem ser relacionadas até certo ponto, talvez até a máxima hidratação, além da qual, a solubilidade pode continuar a aumentar, mas a hidratação não. 
Pode também ocorrer o contrário, CHEFTEL, CUQ, LORIENT [8] afirmaram que a AA aumenta com a diminuição da solubilidade.

Não houve nenhuma atividade do inibidor de tripsina (AIT) nas farinhas extrusadas de milho-soja (70:30) selecionadas, indicando que para as farinhas extrusadas contendo $30 \%$ de soja, as TB adequadas no processo de extrusão para inativarem o inibidor de tripsina foram iguais a 60-90-90-150 (C), 60-90-110-150 (F) e 60-90$130-130^{\circ} \mathrm{C}(\mathrm{G})$, respectivamente.

GUZMAN, MURPHY, JOHNSON [14] observaram que a inativação da AIT aumentou com o aumento das temperaturas de saida do extrusor (de 120 a $160^{\circ} \mathrm{C}$ ), sendo que a mesma foi mais dependente da temperatura em mistura de $70 \%$ de soja para $30 \%$ de milho, e menos dependente em mistura de $80 \%$ de soja para $20 \%$ de milho.

De acordo com LORENZ \& JANSEN [22], a inativação da AIT aumentou para $80 \%$ com a adição de água para uma mistura crua. Uma adição de 3\% de água aumentou a inativação da AIT de 30,6 para 53,7\% em grãos de soja integrais e de 39,1 para $67,8 \%$ em grãos de soja decorticados

\section{4 - CONCLUSÕES}

Nas condições experimentais utilizadas (Extrusor Brabender de dupla rosca com as seguintes especificações: velocidade de alimentação constante de $20,8 \mathrm{Kg} / \mathrm{h}$, velocidade da rotação de parafuso de 100rpm e diâmetro de matriz de $5 \mathrm{~mm}$ ) na realização deste trabalho e de acordo com os resultados obtidos, chegou-se às seguintes conclusões:

- O aumento da temperatura de barril (TB) nas zonas 3 e 4 do extrusor causou um aumento na absorção de água, nitrogênio solúvel em água, índice de solubilidade de nitrogênio, proteina dispersivel em água e indice de dispersibilidade de proteína das farinhas extrusadas de milho-soja (70:30).

\section{5 - REFERÊNCIAS}

[1] AMERICAN ASSOCIATION OF CEREAL CHEMISTS. Approved methods of the American Association of Cereal Chemists. 9.ed. St. Paul:AACC, 1995.

[2] BOOKWALTER, G.N.; MUSTAKAS, G.C.; KWOLEK, W.F.; Mc GHEE, J.E.; ALBRECHT, W.J. Full-fat soy flour extrusion cooked: properties and food uses. Journal of Food Science, v.36, n.1, p.5-9, 1971.

[3] BORDERÍAS, A.J.; MONTERO, P. Fundamentos de la funcionalidad de las proteínas en alimentos. Revista Agroquímica y Tecnologia de Alimentos, v.28, n.2, p.159-169, 1988.

[4] BORGES, G.G.; WANG, S.H.; CABRAL, L.C.; MAIA, L.H.; ASCHERI, J.L.R. Caracterizacion quimica de papillas deshidratadas de grits de maiz e soya. Alimentaria, v.36, n.305, p.111-114, 1999 .

[5] BRESSANI, R.; HERNANDEZ, E.; CÓLON, A.; WOLZAK, A.; GÓMEZ-BRENES, R. Efecto suplementário de tres fuentes de proteína de soya sobre diferentes selecciones o productos de maíz. Archivos Latinoamericanos de Nutrición, v.31, n. 1, p.52-62, 1981.

[6] CHAUHAN, G.S.; BAINS, G.S. Effect of defatted soy flour on the physico-chemical characteristics of extruded rice products. Journal of Food Science and Technology, v.22, n.2, p.115-118, 1985.

[7] CHAUHAN, G.S.; BAINS, G.S. Effect of some extruder variables on physico-chemical properties of extruded ricelegume blends. Food Chemistry, v.27, n.3, p.213-224, 1988.

[8] CHEFTEL, J.C.; CUQ, J.L.; LORIENT, D. Proteínas alimentarias. Zaragoza: Acribia, 1989. $346 \mathrm{p}$.

[9] COCHRAN, W.G.; COX, G.M. Experimental designs, 2.ed. New York: John Wiley, 1957. 611p.

[10] GOMEZ, M.H.; AGUILERA, J.M. Changes in the starch fraction during extrusion-cooking of corn. Journal of Food Science, v.48, n.2, p.378-381, 1983

[11] GONZÁLEZ, R.J.; TORRES, R.L.; DE GREEF, D.M.; GORDO, N.A. Evaluación de almidón de maíz pecocido por extrusión-cocción. Revista Agroquímica y Tecnologia de Alimentos, v.26, n.4, p.552-564, 1986.

[12] GUJSKA, E.; KHAN, K. Functional properties of extrudates from high starch fractions of navy and pinto beans and corn meal blended with legume high protein fractions. Journal of Food Science, v.56, n.2, p.431-435, 1991.

[13] GUTIÉRREZ, M.V.G. de; GÓMEZ, M.H. Modelo para la extrusion de mezclas maíz:soja (70:30). Archivos Latinoamericanos de Nutrición, v.37, n.3, p.494-502, 1987.

[14] GUZMAN, G.J.; MURPHY, P.A.; JOHNSON, L.A. Properties of soybean-corn mixtures processed by low-cost extrusion. Journal of Food Science, v.54, n.6, p.15901593, 1989.

[15] HERMANSSON, A.M. Methods of studying functional characteristics of vegetable proteins. Journal of the American Oil Chemist' Society, v.56, n.3, p.272$278,1979$.

[16] HORVÁTH, E.; CZUKOR, B. Effect of extrusion temperature and initial moisture content on the protein solubility and distribuition in full fat soybean. Acta Alimentaria, v.22, n.2, p.151-167, 1993.

[17] HORVÁTH, E.; PETRES, J.; GELENCSÉR, É.; CZUKOR, B. Effect of extrusion temperature on physico-chemical properties and biological value of soybean-protein. Acta Alimentaria, v. 18, n.2, p.199-211, 1989.

[18] HUTTON, C.W.; CAMPBELL, A.M. Functional properties of a soy concentrate and a soy isolate in simple systems; nitrogen solubility index and water absorption. Journal of Food Science, v.42, n.2, p.454-456, 1977.

[19] JAMES, C.; SLOAN, S. Functional properties of edible rice bran in model systems. Journal of Food Science, v.49, n. 1, p.310-311, 1984.

[20] KAKADE, M.L.; SIMONS, N.R.; LIENER, I.E. An evaluation of natural vs. synthetic substrates for measuring the antitryptic activity of soybean samples. Cereal Chemistry, v.46, n.5, p.518-526, 1969.

[21] KILARA, A.; SHARKASI, T.Y. Effects of temperature on food proteins and its implications on functional properties. Critical Reviews in Food Science and Nutrition, v.23, n.4, p.323-395, 1986.

[22] LORENZ, K.; JANSEN, G.R. Nutrient stability of full-fat soy flour and corn-soy blends produced by low-cost extrusion. Cereal Foods World, v.25, n.4, p.161-162 and $171-172,1980$.

[23] MAIA, L.H.; WANG, S.H.; ASCHERI, J.L.R.; CABRAL, L.C.; FERNANDES, M.S. Viscosidade de pasta, absorção de 
água e índice de solubilidade em água dos mingaus desidratados de arroz e soja. Ciênc. Tecnol. Aliment., v. 19, n.3, p.391-396, 1999.

[24] MAIA, L.H.; WANG, S.H.; FERNANDES, M.S.; CABRAL, L.C. Características químicas dos mingaus desidratados de arroz e soja. Ciênc. Tecnol. Aliment., v.20, n.3, p.416423, 2000.

[25] MATTIL, K.F. The functional requirements of proteins for foods. Journal of the American Oil Chemist' Society, v.48, n.2, p.477-484, 1971 .

[26] MOLINA, M.R.; BRAHAM, J.E.; BRESSANI, R. Some characteristics of whole corn:whole soybean (70:30) and rice:whole soybean (70:30) mixtures processed by simple extrusion cooking. Journal of Food Science, v.48, n.2, p.434-437, 1983

[27] NATH, J.P.; RAO, M.S.N. Functional properties of guar proteins. Journal of Food Science, v.46, n.4, p. 12551259, 1981

[28] NOGUCHI, A.; KUGIMIYA, W.; HAQUE, Z.; SAIO, K. Physical and chemical characteristics of extruded rice flour and rice flour fortified with soybean protein isolate. Journal of Food Science, v.47, n.1, p.240-245, 1981

[29] NYANZI, F.A.; MAGA, J.A.; Effect of processing temperature on detergent-solubilized protein in extrusion-cooked cornstarch/soy protein subunit blends. Journal of Agricultural and Food Chemistry, v.40, n.1, p.131133, 1992.

[30] PHAM, C.B.; DEL ROSARIO, R.R. Studies on the development of texturized vegetable products by the extrusion process. Journal of Food Technology, v. 19, n.5, p.535-547, 1984

[31] PIMENTEL GOMES, F. Curso de estatística experimental. 13.ed. São Paulo: Nobel, 1991. 468p.

[32] SHEARD, P.R.; FELLOWS, A.; LEDWARD, D.A.; MITCHELL, J.R. Macromolecular changes associated with the heat treatment of soya isolate. Journal of Food Technology, v.21, n.1, p.55-60, 1986.

[33] SOSULSKI, F.W. The centrifuge method for determining flour absorption in hard red spring wheats. Cereal Chemistry, v.39, n.4, p.344-350, 1962.

[34] TANG, J.; DING, X.L. Relationship between functional properties and macromolecular modifications of extruded corn starch. Cereal Chemistry, v.71, n.4, p.364-369, 1994.

[35] VAN DE KAMER, J.H.; VAN GINKEL, L. Rapid determination of crude fiber in cereals. Cereal Chemistry, v.29, n.4, p. 239-251, 1952 .

[36] VISSER, A.; THOMAS, A. Review: Soya protein products their processing, functionality, and application aspects. Food Reviews International, v.3, n.1-2, p.1-32, 1987.

[37] VOLKERT, M.A.; KLEIN, B.P. Protein dispersibility and emulsion characteristics of flour soy products. Journal of Food Science, v.44, n.1, p.93-96, 1979.

[38] WAGNER, J.R.; AÑON, M.C. Influence of denaturation, hydrophobicity and sulfhydryl content on solubility and water absorbing capacity of soy protein isolates. Journal of Food Science, v.55, n.3, p.765-770, 1990.

[39] WANG, S.H.; ASCHERI, J.L.R.; OLIVEIRA, M.F.; FERNANDES, M.S. Características tecnológicas y sensoriales de harinas de arroz-soya (70:30) extruídas para uso como papilla instantánea. Alimentaria, v.38, n.324, p.77-84, 2001.

[40] WANG, S.H.; BORGES, G.G.; CABRAL, L.C.; ARAUJO, F.B. Efeito da proporção canjiquinha:soja na solubilidade, dispersibilidade e propriedades emulsificantes de mingaus desidratados obtidos a partir de diferentes proporções desses ingredientes. Pesquisa Agropecuária Brasileira, v. 36, n.2, p.357-362, 2001.

[41] WANG, S.H.; SILVA, F.C.; BORGES, G.G.; ASCHERI, J.L.R.; CABRAL, L.C. Propiedades reológicas y sensoriales de papillas reconstituídas a base de grits de maíz y soya. Alimentaria, v.36, n.305, p.135-140, 1999.

[42] WANG, S.H.; ZOIA, W.F. Propriedades funcionais de misturas de fubá mimoso e farinha de soja desengordurada. Pesquisa Agropecuária Brasileira, v.29, n. 12 p. 1979-1985, 1994.

[43] WHALEN, P.J.; BASON, M.L.; BOOTH, R.I.; WALKER, C.E.; WILLIAMS, P.J. Measurement of extrusion effects by viscosity profile using the rapid viscoanalyser. Cereal Foods World, v.42, n.6, p.469-475, 1997.

[44] YASUMATSU, K.; SAWADA, K.; MORITAKA, S.; TODA, J.; WADA, T.; ISHI, K. Effect of addition of soybean products on dough properties. Agricultural and Biological Chemistry, v.36, n.5, p.729-735, 1972.

[45] ZHU, S.; RIAZ, M.N.; LUSAS, E.W. Effect of different extrusion temperatures and moisture content on lipoxigenase inactivation and protein solubility in soybeans. Journal of Agricultural and Food Chemistry, v.44, n.10, p.3315-3318, 1996.

[46] ZOIA, W.F.; WANG, S.H.; SGARBIERI, V.C. Características sensoriais e nutricionais de angus fortificados com diferentes niveis de farinha de soja desengordurada. Alimentos e Nutrição, v.8, p.49-56, 1997. 